\title{
Is Human Capital the Sixth Factor? Evidence from US Data
}

\author{
Rahul Roy*, Santhakumar Shijin \\ Pondicherry University, India
}

Article history:

Received:

Revised:

Accepted:

Published:
$13 / 11 / 2018$

$15 / 01 / 2019$

$18 / 02 / 2019$

$11 / 03 / 2019$

\section{Abstract}

Problem/Relevance: Measuring the risk of an asset and the economic forces driving the price of the risk is a challenging task that preoccupied the asset pricing literature for decades. However, there exists no consensus on the integrated asset pricing framework among the financial economists in the contemporaneous asset pricing literature. Thus, we consider and study this research problem that has greater relevance in pricing the risks of an asset. In this backdrop, we develop an integrated equilibrium asset pricing model in an intertemporal (ICAPM) framework.

Research Objective/Questions: Broadly we have two research objectives. First, we examine the joint dynamics of the human capital component and common factors in approximating the variation in asset return predictability. Second, we test whether the human capital component is the unaccounted and the sixth pricing factor of $\mathrm{FF}$ five-factor asset pricing model. Additionally, we assess the economic and statistical significance of the equilibrium six-factor asset pricing model.

Methodology: The human capital component, market portfolio, size, value, profitability, and investment are the pricing factors of the equilibrium six-factor asset pricing model. We use Fama-French (FF) portfolios of $2 \times 3,5 \times 5,10 \times 10$ sorts, $2 \times 4 \times 4$ sorts, and the Industry portfolios to examine the equilibrium six-factor asset pricing model. The Generalized method of moments (GMM) estimation is used to estimate the parameters of variant asset pricing models and Gibbons-Ross-Shanken test is employed to evaluate the performance of the variant asset pricing frameworks.

Major Findings: Our approaches led to three conclusions. First, the GMM estimation result infers that the human capital component of the six-factor asset pricing model significantly priced the variation in excess return on FF portfolios of variant sorts and the Industry portfolios. Further, the sensitivity to human capital component priced separately in the presence of the market portfolios and the common factors. Second, the six-factor asset pricing model outperforms the CAPM, FF three-factor model, and FF five-factor model, which indicates that the human capital component is a significant pricing factor in asset return predictability. Third, we argue that the human capital component is the unaccounted asset pricing factor and equally the sixth-factor of the FF five-factor asset pricing model. The additional robustness test result confirms that the parameter estimation of the six-factor asset pricing model is robust to the alternative definitions of the human capital component.

Implications: The empirical results and findings equally pose the more significant effects for the decision-making process of the rational investor, institutional managers, portfolio managers, and fund managers in formulating the better investment strategies, which can help in diversifying the aggregate risks.

\footnotetext{
* Corresponding author.

E-Mail address: rahulroy819@gmail.com

ORCID: 0000-0001-7526-2396
} 
Keywords: Asset pricing; FF five-factor model; human capital; return predictability; six-factor asset pricing model; sixth factor.

JEL classification: E24; G11; G12

\section{Introduction}

Pricing the risk of an asset and the economic forces governing the price of the risks are the challenging issues that preoccupied the asset pricing literature for decades. In this succession Lintner (1965), Mossin (1966) and Sharpe (1964) developed the capital asset pricing model (CAPM), which measures the risks of an asset by the covariance of asset's return with the return on all invested wealth of an economy, also known as the 'market portfolio'. The market portfolio in empirical research is usually proxied by the yield on the value-weighted stock market index. Blume \& Friend (1973) estimated an equilibrium model and suggested that the price of the market portfolio is the relative risk aversion of the representative agent.

Even though the practitioners primarily use the CAPM because of its practical implications, it faced several criticisms from various directions. Merton (1973) criticized the assumptions drawn to derive the model whereas a group of researchers emphasized that the risk of an asset is measured by its covariance with the marginal utility of the representative agents. In the intertemporal framework, the innovations in marginal utility can be determined through changing expectations of future returns, which not only drive the marginal productivity of wealth but the increment to wealth itself.

The most critical assumption considered to test the CAPM is that the aggregate stock market index can adequately proxy the market portfolio as opposed by Roll (1977). Based on the argument that the return on the market portfolio cannot be measured accurately by the yield on the stock market index. In response to these criticisms, a handful of financial economists favored multi-factor models, in which the covariances measure the risk with the common factors. Following Chen et al. (1986) employ a multi-factor model to price the risk, consisting of innovations to essential macroeconomic variables witnessed a better empirical fit to the cross-sectional asset returns data. These sort of multi-factor models needs weak theoretical assumptions.

Consequently, Fama \& French (1993) introduced a three-factor model consisting of size, bookto-market, and market portfolio as the asset pricing factors. The Fama-French (FF) three-factor model fits the cross-sectional returns data remarkably well. In the spirit of the factor-based model, Carhart (1997) accommodated momentum as a pricing factor to the FF three-factor model and proposed a four-factor framework. Further, the empirical results suggest that the sensitivity to momentum strategy priced separately in the presence of FF pricing factors. The greater empirical success of the factor-based asset pricing models has been witnessed in the asset pricing literature but fails to provide the economic justification. Concurrently, Fama \& French (2015) proposed a fivefactor model by adding profitability and investment factors to the FF three-factor model, which performs poorly because of its inability to capture the low average returns on small stocks. Inaddition, Fama \& French (2017); Gregoriou, Racicot, \& Théoret (2016); and Racicot \& Rentz (2016) confirms the failure of the FF five-factor asset pricing model in asset return predictability.

Moreover, the sizeable empirical evidence favoring the factor-based models in the asset pricing literature fail to resolve the two critical issues. First, how the risk of an asset be measured? Second, what dynamic economic forces drive the price of the risk? 
Campbell (1996) employ a multi-factor model in an intertemporal framework, which consists of innovations in return on market portfolio and human capital ${ }^{1}$ component as the pricing factors. He concluded that the coefficient of relative risk aversion is relatively higher than the price of the risk attached to the market portfolio. Lustig \& Van Nieuwerburgh (2008) opines that the human capital and financial wealth ${ }^{2}$ equally play an important role in pricing the risk of an asset, and the joint dynamics of both the components possess more significant implications for aggregate wealth ${ }^{3}$ dynamics. Campbell (2000) estimated labor income is two-thirds of United States (US) GDP (Gross domestic product) whereas the capital income is mere one-third of GDP. Lustig et al. (2013) argue that the financial (stock market) wealth is mere $1 \%$ and all non-human wealth is only $8 \%$, whereas $92 \%$ is human wealth among the aggregate household wealth of US. Following, Palacios (2015) suggest that the share of human capital in the total wealth is approximately $93 \%$.

Berk \& Walden (2013); Betermier, Jansson, Parlour, \& Walden (2012); Lustig \& Van Nieuwerburgh (2008); and Santos \& Veronesi (2006) provide the empirical evidence that human capital component is highly correlated with the expected stock returns. Similarly, Campbell (1996) suggest that introducing FF pricing factors to their intertemporal capital asset pricing (ICAPM) framework that consists of the human capital component along with macroeconomic variables may yield better results, which further deepen our understanding of dynamics governing the risk and return relationship. Subsequently, Roy \& Shijin (2018) developed an equilibrium multifactor asset pricing model consisting of the market portfolio, human capital, bond market factors, and FF factors alongside the momentum factor. They test the equilibrium model in both ICAPM and consumptionbased CAPM (CCAPM) frameworks across the economies. Further, they conclude that the market portfolio and human capital component are the only significant priced factors in return predictability across the marketplaces, and FF factors, bond market factors, and momentum factor becomes redundant. These findings along with the human capital backed asset pricing literature indicating the importance of the human capital component in asset return predictability.

The joint dynamics of the financial and human wealth components shares and drives the dynamics in aggregate wealth of an economy is well documented in the asset pricing literature. Simultaneously, there exists evidence in the asset pricing literature that the sensitivity of the human capital beta is over and above the sensitivity of market returns beta in the asset return predictability. However, there exist the greater indifference of consensus between the proponents supporting factorbased asset pricing framework and the proponents favoring the human capital adjusted asset pricing framework. The lack of agreement between these proponents and similarly the unavailability of an integrated asset pricing framework motivates us to study these issues thoroughly and provide the cohesive explanation, which can develop the consensus between both the approaches. Hence, we undertake this complex issue persisting in the asset pricing literature, which has a greater emphasis for the rational investors, fund managers, institutional investment managers, and relative key stakeholders concerning their investment strategies formulation and decision-making process.

We follow the suggestion made by Campbell (1996) and model the human capital component along with the FF asset pricing factors (common factors) in an ICAPM framework to price the risk associated with an asset. Hence, by doing so, we tend to draw an intertemporal structure that satisfies

${ }^{1}$ Human capital as defined in macroeconomics, is the sum of the discounted value of current and future labor income
(Fama \& Schwert, 1977; Lettau \& Ludvigson, 2001; Mayers, 1972; Ren, Yuan, \& Zhang, 2014; Sousa, 2012a, 2012b).

${ }^{2}$ Financial wealth is the tradable financial assets, which proxied by aggregate stock index (Campbell, 2015).

${ }^{3}$ Aggregate wealth is the sum of human capital and asset holdings (Jagannathan \& Wang, 1996). 
the conditions of both the proponents where human capital component and common factors jointly assess the risks of an asset. Further, the inclusion of human capital component with the FF five-factor model consisting of the market portfolio, size, value, investment, and profitability as the pricing factors would suffice the issue of an integrated equilibrium asset pricing model. Further, the ICAPM framework would also uncover the puzzle, whether the human capital component is the sixth factor. Briefly, we study the objectives of this paper into two phases. First, we test the joint dynamics of the human capital component and common factors in asset return predictability. Second, we check whether the human capital component is the sixth factor. Further, we also examine the economic and statistical significance of our equilibrium six-factor asset pricing model.

To achieve the objectivity of the study, we use the generalized method of moments (GMM) to uncover the joint dynamics of the human capital component and common factors in asset return predictability. Similarly, we use the GRS (Gibbons-Ross-Shanken) test statistics of Gibbons et al. (1989) to evaluate the economic and statistical performance of the variant asset pricing models. We employ FF $2 \times 3,5 \times 5$, and $10 \times 10$ sorts of Size-B/M, Size-OP, Size-Investment portfolios, $2 \times 4 \times$ 4 sorts of Size-B/M-OP, Size-B/M-Investment, Size-OP-Investment portfolios, and the sets of 5, 10, $12,17,30,48$, and 49 Industry portfolios, to test the significance of the models used in the study. We revisit the CAPM, FF three-factor model, and FF five-factor models to check and evaluate the statistical and economic viability of the proposed six-factor asset pricing model.

Our approaches led to three conclusions. First, the GMM estimation results show that the human capital component of the six-factor asset pricing framework significantly priced the variation in excess return on the FF portfolios of $2 \times 3,5 \times 5,10 \times 10,2 \times 4 \times 4$ sorts and the Industry portfolios. Moreover, the empirical results further reveal that the sensitivity of the human capital component priced separately in the presence of the market portfolio and the common factors. Second, GRS test rejects the CAPM, FF three-factor model, and FF five-factor model whereas the six-factor asset pricing model convincingly passes the GRS test across the FF portfolios of variant sorts and the FF Industry portfolios. These results indicate that human capital is indeed a significant component of aggregate wealth and equally a key asset pricing factor in asset return predictability. Third, the GMM estimation and GRS test results infer that our proposed integrated equilibrium six-factor asset pricing model is statistically and economically capable of assessing the variation in excess returns across the FF variant portfolios. Conclusively, we argue that the human capital component is an unaccounted pricing factor and undoubtedly the sixth-factor of the FF five-factor asset pricing model.

The paper is organized as follows. The second section presents the data and variable definitions. The third section shows the mathematical notations of the variant asset pricing models. The fourth section reports the summary statistics of the explanatory variables. In the fifth section, we discuss the empirical results of the variant asset pricing frameworks. The sixth section discusses the results of additional tests for robustness. Following, we give the empirical interpretation and summary of the study in section seven. The last section presents the concluding remarks.

\section{Data and variable definitions}

We develop an integrated equilibrium six-factor asset pricing framework consisting of the human capital component, market portfolio, and common factors as the underlying pricing factors. Specifically, the priced factors include labor income growth (LBR) and wealth-to-consumption ratio (WCR) measuring the return on human capital, value-weighted market index (RM-RF) measuring return on market portfolio, size (SMB), value (HML), profitability (RMW), investment (CMA), 
alongside momentum (WML). The brief description and definition of explanatory variables and the source of data collection are shown in Table 1 . We use the FF portfolios of $2 \times 3,5 \times 5,10 \times 10$ sorts on size-B/M, size-OP, size-Investment, $2 \times 4 \times 4$ sorts on Size-B/M-OP, Size-B/M-Investment, SizeOP-Investment, and the Industry portfolios to assess the significance and performance of the variant asset pricing models along with the equilibrium six-factor asset pricing framework developed in the study. The data of FF test portfolio is retrieved from French - Data Library (http://mba.tuck.dartmouth.edu/pages/faculty/ken.french/data_library.html). All the returns are expressed in US dollar (USD). The time-series dataset representing the variables are expressed in monthly frequency and the sample period ranges from January 1986 to December 2014. We discuss the econometric methodology in the following section. 
Table 1 Variables definition and data specification

\begin{tabular}{|c|c|c|c|}
\hline Variable code & Variable & Variable definition & Data source \\
\hline RM-RF & Aggregate market & $\begin{array}{l}\text { RM-RF is the excess return on the market, value-weight return on all the firms } \\
\text { incorporated in the US and listed on the NYSE, AMEX, and NASDAQ minus the } \\
\text { one month Treasury Bill rate }\end{array}$ & French (2019) \\
\hline $\mathrm{SMB}$ & Small Minus Big & $\begin{array}{l}\text { SMB is the difference between the average returns on the three small-stock portfolios } \\
\text { ( } \mathrm{SL} / \mathrm{BM}, \mathrm{SM} / \mathrm{BM} \text {, and } \mathrm{SH} / \mathrm{BM}) \text { and the average returns on the three big-stock } \\
\text { portfolios }(\mathrm{BL} / \mathrm{BM}, \mathrm{BM} / \mathrm{BM} \text {, and } \mathrm{BH} / \mathrm{BM})\end{array}$ & French (2019) \\
\hline HML & High Minus Low & $\begin{array}{l}\mathrm{HML} \text { is the difference between the average returns on the two value portfolios } \\
(\mathrm{SH} / \mathrm{BM} \text { and } \mathrm{BH} / \mathrm{BM}) \text { and the average returns on the two growth portfolios } \\
(\mathrm{SL} / \mathrm{BM} \text { and } \mathrm{BL} / \mathrm{BM})\end{array}$ & French (2019) \\
\hline RMW & Robust Minus Weak & $\begin{array}{l}\text { RMW is the difference between the average return on two robust operating } \\
\text { profitability portfolios (S/HOP and B/HOP) and the average return on two weak } \\
\text { operating profitability portfolios ( } / \mathrm{LOP} \text { and } \mathrm{B} / \mathrm{LOP})\end{array}$ & French (2019) \\
\hline CMA & $\begin{array}{l}\text { Conservative Minus } \\
\text { Aggressive }\end{array}$ & $\begin{array}{l}\text { CMA is the difference between the average return on two conservative investment } \\
\text { portfolios (S/LoINV and B/LoINV) and the average return on two aggressive } \\
\text { investment portfolios ( } / \mathrm{HiINV} \text { and } \mathrm{B} / \mathrm{HiINV} \text { ). }\end{array}$ & French (2019) \\
\hline LBR & Labor income growth & $\begin{array}{l}\text { The aggregate of salaries and wages component from earnings report of the firms } \\
\text { listed on the NYSE, AMEX, and NASDAQ }\end{array}$ & $\begin{array}{l}\text { Thomson Reuters - } \\
\text { Datastream }\end{array}$ \\
\hline WCR & Wealth-to-consumption ratio & $\begin{array}{l}\text { Dividing wages with the consumption of consumer goods includes both durables } \\
\text { and non-durables. The Consumption data are collected from Bloomberg database }\end{array}$ & $\begin{array}{l}\text { Thomson Reuters - } \\
\text { Datastream }\end{array}$ \\
\hline
\end{tabular}

Notes: All returns are in USD (US dollar). The datasets are expressed in monthly frequency. We follow Campbell (1996) to construct labor income growth measure of human capital. 


\section{Econometric methodology}

Empirically, the cost of equity for the stock $i$ may be expressed as

$$
\boldsymbol{R}_{i}-\boldsymbol{R}_{f}=\alpha_{i}+\sum_{k=1}^{n} \delta_{k} \beta_{i k}+\varepsilon_{i}
$$

Where $\boldsymbol{n}=1$ for the CAPM, $\boldsymbol{n}=3$ for FF three-factor model, $\boldsymbol{n}=5$ for FF five-factor model, and $\boldsymbol{n}=6$ for the equilibrium six-factor framework. $\alpha_{i}$ is the abnormal return for the stock $i$, $\delta_{k}$ is the proxy for the unobservable variable $\delta_{k}^{\delta}$, and $\varepsilon_{i}$ is the white noise process.

Following the above framework, equation (2) is the empirical formulation of the CAPM takes the form

$$
\boldsymbol{R}_{i t}-\boldsymbol{R}_{f t}=\alpha_{i}+\beta_{1 i}(\boldsymbol{R M}-\boldsymbol{R} \boldsymbol{F})_{t}+\varepsilon_{i t}
$$

Where $\boldsymbol{R}_{i t}-\boldsymbol{R}_{f t}$ is the excess returns over the risk-free return of the portfolio $i$ at the time $t . \beta_{1}$ captures the sensitivity of market portfolio at time $t$.

Equation (3) is the GMM formulation of equation (2).

$$
\boldsymbol{R}_{i t}-\boldsymbol{R}_{f t}=\alpha_{G M M i}+\beta_{G M M 1 i}(\boldsymbol{R M}-\boldsymbol{R F})_{t}+\varepsilon_{i t}
$$

Equation (4) is the empirical formula of FF three-factor model takes the form

$$
\boldsymbol{R}_{i t}-\boldsymbol{R}_{f t}=\alpha_{i}+\beta_{1 i}(\boldsymbol{R M}-\boldsymbol{R F})_{t}+\beta_{2 i} S M B_{t}+\beta_{3 i} \boldsymbol{H M L} \boldsymbol{L}_{t}+\varepsilon_{i t}
$$

Where $\boldsymbol{R}_{i t}-\boldsymbol{R}_{f t}$ is the excess returns over the risk-free return of the portfolio $i$ at the time $t . \beta_{1}$, $\beta_{2}$, and $\beta_{3}$ capture the sensitivity of market portfolio, size, and value, respectively at time $t$.

Equation (5) is the GMM formulation of equation (4).

$$
\boldsymbol{R}_{i t}-\boldsymbol{R}_{f t}=\alpha_{G M M i}+\beta_{G M M 1 i}(R M-R F)_{t}+\beta_{G M M 2 i} S M B_{t}+\beta_{G M M 3 i} H M L_{t}+\varepsilon_{i t}
$$

Equation (6) is the empirical formulation of FF five-factor model takes the form

$$
\boldsymbol{R}_{i t}-\boldsymbol{R}_{f t}=\alpha_{i}+\beta_{1 i}(\boldsymbol{R M}-\boldsymbol{R F})_{t}+\beta_{2 i} S M B_{t}+\beta_{3 i} H M L_{t}+\beta_{4 i} R M W_{t}+\beta_{5 i} C M A_{t}+\varepsilon_{i t}
$$

Where $\boldsymbol{R}_{i t}-\boldsymbol{R}_{f t}$ is the excess returns over the risk-free return of the portfolio $i$ at the time t. $\beta_{1}, \beta_{2}, \beta_{3}, \beta_{4}$, and $\beta_{5}$ captures the sensitivity of market portfolio, size, value, profitability, and investment, respectively at time $t$. 
Equation (7) is the GMM formulation of equation (6).

$$
\begin{aligned}
\boldsymbol{R}_{i t}-\boldsymbol{R}_{f t}= & \alpha_{G M M i}+\beta_{G M M 1 i}(\boldsymbol{R M}-\boldsymbol{R F})_{t}+\beta_{G M M 2 i} S M B_{t}+\beta_{G M M 3 i} H M L_{t}+\beta_{G M M 4 i} R M W_{t} \\
& +\beta_{G M M S i} C M A_{t}+\varepsilon_{i t}
\end{aligned}
$$

Equation (8) is the empirical formulation of equilibrium six-factor asset pricing model proposed in the study takes the form

$$
\boldsymbol{R}_{i t}-\boldsymbol{R}_{f t}=\alpha_{i}+\beta_{1 i} \boldsymbol{L B R}+\beta_{2 i}(\boldsymbol{R M}-\boldsymbol{R F})_{t}+\beta_{3 i} S M B_{t}+\beta_{4 i} H M L_{t}+\beta_{5 i} R M W_{t}+\beta_{6 i} C M A_{t}+\varepsilon_{i t}
$$

Where $\boldsymbol{R}_{i t}-\boldsymbol{R}_{f t}$ is the excess returns over the risk-free return of the portfolio $i$ at the time $t . \beta_{1}$, $\beta_{2}, \beta_{3}, \beta_{4}, \beta_{5}$, and $\beta_{6}$ captures the sensitivity of labor income growth measuring human capital, market portfolio, size, value, profitability, and investment, respectively at time $t$.

Equation (9) is the GMM formulation of equation (8).

$$
\begin{aligned}
\boldsymbol{R}_{i t}-\boldsymbol{R}_{f t}= & \alpha_{G M M i}+\beta_{G M M 1 i} \boldsymbol{L B R _ { t }}+\beta_{G M M 2 i}(\boldsymbol{R M}-\boldsymbol{R F})_{t}+\beta_{G M M 3 i} S M B_{t}+\beta_{G M M 4 i} H M L_{t} \\
& +\beta_{G M M 5 i} R M W_{t}+\beta_{G M M{ }_{6 i}} C M A_{t}+\varepsilon_{i t}
\end{aligned}
$$

\section{GRS test}

GRS test statistic proposed by Gibbons et al. (1989) is used to test the performance of the CAPM, FF three-factor, FF five-factor, and the equilibrium six-factor models, respectively.

$$
\boldsymbol{G R S} \equiv\left(\frac{\boldsymbol{T}-\boldsymbol{N}-\boldsymbol{K}}{\boldsymbol{N}}\right)\left(1+\hat{\mu}^{\prime} \hat{\Omega}^{-1} \hat{\mu}\right)^{-1} \hat{\alpha}^{\prime} \hat{\Sigma}^{-1} \hat{\alpha}: \boldsymbol{F}(\boldsymbol{N}, \boldsymbol{T}-\boldsymbol{N}-\boldsymbol{K})
$$

Where $T$ is the total number of observations in the time-series, $N$ is the number of portfolios. $K$ is the number of factors in the asset pricing models (hence $K=1$ for the CAPM, $K=3$ for the FF three-factor model, $K=5$ for the FF five-factor model, and $K=6$ for the six-factor model. $\hat{\boldsymbol{a}}$ is an $N$ by one vector of estimated alphas, $\hat{\Sigma}$ is an $N$ by $N$ matrix that holds the unbiased estimate of the residual variance-covariance matrix. $\hat{\mu}$ is a $K$ by one vector of sample means of the portfolio's average returns, and $\hat{\Omega}$ is a $K$ by $K$ matrix that holds the unbiased estimate of the portfolios' covariance matrix. Assuming that the residual are independently and normally distributed, and uncorrelated with the returns on the model's factors, the GRS statistic follows an F-distribution with $N$ degrees of freedom in the denominator and $T-N-K$ degrees in the numerator under the null of zero alphas. Along with GRS statistics, we calculate the following test statistics to test if all alphas are jointly equal to zero,

$$
\boldsymbol{T}\left(1+\hat{\mu}^{\prime} \hat{\Omega}^{-1} \hat{\mu}\right)^{-1} \hat{\alpha}^{\prime} \hat{\Sigma}^{-1} \hat{\alpha}: \chi_{N}^{2}
$$


This test statistics do not require the normality of error terms. Further, it follows an asymptotic $\chi^{2}$ distribution with $\mathrm{N}$ degrees of freedom in the null hypothesis of zero alphas assuming homoscedasticity.

Relevance test for explanatory variables

Weak instrument occurs when the $((1) /(\boldsymbol{n})) \boldsymbol{Z}^{\prime} \boldsymbol{X}$ is close to zero. In line with Olea \& Pflueger (2013), using the conventional $F$ statistic for testing that all the coefficients in the regression $\boldsymbol{x}_{\boldsymbol{i}}=\boldsymbol{z}_{i}^{\prime} \pi+v_{i}$ (12) are 0 . This specification is used to test the hypothesis that the instruments are weak. In other words, this is a test of the relevance of the instruments. Explicitly, we assess each explanatory variable used in the six-factor asset pricing model by estimating regression (12) on all the instruments. According to Olea \& Pflueger (2013), if the resulting $F$ statistic is below 24.00 for all the regressions (of explanatory variables), this indicates the possible weak instruments problem.

Conversely, if at least one of the $F$ values ( $F$-statistic) is above 24.00 , then the instruments are robust. Note (from Table 2) all the $F$ values are well-over 24.00. The instrumental variables coefficients represent the partial correlation with the explanatory variables. Beginning with the coefficient of $Z_{\mathrm{LBR}}$ on $X_{\mathrm{LBR}}$ and ending with the coefficient of $Z_{\mathrm{CMA}}$ on $X_{\mathrm{CMA}}$, these diagonal coefficients are all close to 1.000 and possess significant $t$ values ( $t$-statistic), which indicates that particular instrument is highly related to its individual explanatory variable. The $p$-value (not reported) of the off-diagonal coefficients are relatively and statistically significant at 5\% level (statistically significant for the utmost cases). We report the summary statistics of explanatory variables in the successive section. 
R. Roy, S. Shijin / ACRN Journal of Finance and Risk Perspectives 8 (2019) 21 - xx

Table 2 Relevance test for explanatory variables

\begin{tabular}{|c|c|c|c|c|c|c|c|c|c|}
\hline & $\alpha$ & $Z_{\mathrm{LBR}}$ & $Z_{\mathrm{WCR}}$ & $Z_{\mathrm{RM}-\mathrm{RF}}$ & $Z_{\mathrm{SMB}}$ & $Z_{\mathrm{HML}}$ & $Z_{\mathrm{RMW}}$ & $Z_{\mathrm{CMA}}$ & F-statistic \\
\hline \multirow[t]{2}{*}{$X_{\mathrm{LBR}}$} & $-4.71 \mathrm{E}-13$ & 1.000 & & $9.81 \mathrm{E}-16$ & $-1.44 \mathrm{E}-15$ & $-1.69 \mathrm{E}-15$ & $4.92 \mathrm{E}-16$ & $3.59 \mathrm{E}-15$ & $8.10 \mathrm{E}+28$ \\
\hline & -18.417 & $6.94 E+14$ & & 1.411 & -1.442 & -1.313 & 0.386 & 1.940 & \\
\hline \multirow[t]{2}{*}{$X_{\mathrm{WCR}}$} & $0.00 \mathrm{E}+00$ & & 1.000 & $2.40 \mathrm{E}-17$ & $3.58 \mathrm{E}-17$ & $-1.37 \mathrm{E}-17$ & $1.06 \mathrm{E}-16$ & $0.00 \mathrm{E}+00$ & $2.24 \mathrm{E}+33$ \\
\hline & 0.000 & & $1.15 E+17$ & 7.248 & 7.511 & -2.236 & 17.481 & 0.000 & \\
\hline \multirow[t]{2}{*}{$X_{\mathrm{RM}-\mathrm{RF}}$} & $0.00 \mathrm{E}+00$ & $5.37 \mathrm{E}-18$ & & $1.00 \mathrm{E}+00$ & $0.00 \mathrm{E}+00$ & $0.00 \mathrm{E}+00$ & $0.00 \mathrm{E}+00$ & $0.00 \mathrm{E}+00$ & $7.06 \mathrm{E}+35$ \\
\hline & 0.000 & $4.59 E+00$ & & $1.77 E+18$ & 0.000 & 0.000 & 0.000 & 0.000 & \\
\hline \multirow[t]{2}{*}{$X_{\mathrm{SMB}}$} & $3.68 \mathrm{E}-15$ & $-2.10 \mathrm{E}-16$ & & 4.23E-17 & $1.00 \mathrm{E}+00$ & $-4.76 \mathrm{E}-17$ & $4.75 \mathrm{E}-18$ & $6.34 \mathrm{E}-17$ & $2.32 \mathrm{E}+33$ \\
\hline & 15.023 & $-1.52 E+01$ & & $6.35 E+00$ & $1.04 E+17$ & -3.869 & 0.389 & 3.574 & \\
\hline \multirow[t]{2}{*}{$X_{\mathrm{HML}}$} & 0.000 & $2.69 \mathrm{E}-18$ & & $-2.12 \mathrm{E}-17$ & $-3.19 \mathrm{E}-17$ & 1.000 & 0.000 & 0.000 & $2.07 \mathrm{E}+33$ \\
\hline & 0.000 & 0.190 & & -3.104 & -3.257 & $7.95 E+16$ & 0.000 & 0.000 & \\
\hline
\end{tabular}


R. Roy, S. Shijin / ACRN Journal of Finance and Risk Perspectives 8 (2019) 21 - 55

\begin{tabular}{|c|c|c|c|c|c|c|c|c|c|}
\hline & $\alpha$ & $Z_{\mathrm{LBR}}$ & $Z_{\mathrm{WCR}}$ & $Z_{\mathrm{RM}-\mathrm{RF}}$ & $Z_{\mathrm{SMB}}$ & $Z_{\mathrm{HML}}$ & $Z_{\mathrm{RMW}}$ & $Z_{\mathrm{CMA}}$ & F-statistic \\
\hline \multirow[t]{2}{*}{$X_{\mathrm{RMW}}$} & $3.68 \mathrm{E}-15$ & $-2.12 \mathrm{E}-16$ & & $4.23 \mathrm{E}-17$ & $6.38 \mathrm{E}-17$ & $-6.70 \mathrm{E}-17$ & 1.000 & $-1.68 \mathrm{E}-16$ & $2.88 \mathrm{E}+32$ \\
\hline & 6.075 & -6.221 & & 2.568 & 2.694 & -2.203 & $3.32 E+16$ & -3.823 & \\
\hline \multirow[t]{2}{*}{$X_{\mathrm{CMA}}$} & $-2.21 \mathrm{E}-14$ & $1.26 \mathrm{E}-15$ & & $-4.23 \mathrm{E}-17$ & $-1.08 \mathrm{E}-16$ & $6.70 \mathrm{E}-17$ & $-1.78 \mathrm{E}-16$ & 1.000 & $4.13 E+31$ \\
\hline & -17.798 & 18.033 & & -1.254 & -2.230 & $1.08 E+00$ & -2.888 & $1.11 E+16$ & \\
\hline
\end{tabular}

Notes: The aggregate of 348 observations is used to calculate the descriptive statistics. The values with italic phase signify the $t$-statistic of the respective $\beta$ coefficient of the instruments. The values with bold phase signify the $F$ value ( $F$-statistic) more than 24.00 for the respective regression of the explanatory variable. 


\section{Summary statistics of explanatory variables}

The summary statistics of explanatory variables are reported in Table 3 . The average excess value-weighted market returns (equity premium) over the one-month Treasury bill for the US is $0.656 \%$ per month $(\mathrm{t}=2.714)$. The size and value premiums are $0.102 \%(\mathrm{t}=0.625)$ and $0.244 \%(\mathrm{t}=1.545)$ per month respectively. Likewise, the profitability and investment premiums are $0.363 \%(t=2.550)$ and $0.320 \%(t=2.060)$ per month respectively for US. The average labor income growth and the wealth-to-consumption ratio, the aggregate measure of human capital are $17.620 \%(\mathrm{t}=174.890)$ and $1.973 \%(\mathrm{t}=24.715)$ per month respectively. The empirical estimation results of the asset pricing frameworks are reported in the following section.

Table 3 Summary statistics of the explanatory factors

\begin{tabular}{llll}
\hline & $\mu$ & $\sigma$ & $t(\mu)$ \\
\hline RM-RF & 0.656 & 4.507 & 2.714 \\
SMB & 0.102 & 3.047 & 0.625 \\
HML & 0.244 & 2.947 & 1.545 \\
RMW & 0.363 & 2.653 & 2.550 \\
CMA & 0.320 & 2.060 & 2.894 \\
LNLBR & 17.620 & 1.879 & 174.890 \\
LNWCR & 1.973 & 1.489 & 24.715
\end{tabular}

Notes: $\mu$ and $\sigma$ are the mean and standard deviation of the explanatory factors. $t(\mu)$ is the ratio of Mean to its standard error.

\section{Empirical estimation results of asset pricing framework}

The GMM estimation results of FF portfolios of $2 \times 3,5 \times 5,10 \times 10$ sorts are shown in Table $4,2 \times 4 \times 4$ sorts in Table 6 , and Industry portfolios in Table 8 . Similarly, the summary statistics of GRS test of FF portfolios of $2 \times 3,5 \times 5,10 \times 10$ sorts are reported in Table 5, $2 \times$ $4 \times 4$ sorts in Table 7 , and Industry portfolios in Table 9 .

Portfolios of $2 \times 3$ sorts

Panel A of Table 4 shows the GMM estimation result for $2 \times 3$ sorts of Size-B/M portfolios. The GMM estimation result infers that the human capital component of the six-factor model significantly priced the variation in excess return on three of $2 \times 3$ sorts of Size-B/M portfolios. Panel A of Table 5 presents the GRS test results of CAPM, FF three-factor, FF five-factor, and the six-factor models in approximating the excess return on $2 \times 3$ sorts of Size-B/M portfolios. The $p$-value of GRS test statistic rejects the null hypothesis of zero intercepts of CAPM, FF three-factor, and FF five-factor models for $2 \times 3$ sorts of Size-B/M portfolios. In 
line with our argument that human capital is a significant component of the six-factor asset pricing model, the $p$-value of GRS test statistic unable to reject the null hypothesis of zero intercepts of the six-factor model. Following, the six-factor model passes the GRS test for $2 \times$ 3 sorts of Size-B/M portfolios. The average $A R^{2}$ of the six-factor model is 0.972 .

Panel A of Table 4 reports the GMM estimation result for $2 \times 3$ sorts of Size-OP portfolios. The GMM estimation result indicates that the human capital component of the six-factor model significantly priced the variation in excess return on three of $2 \times 3$ sorts of Size-OP portfolios. Panel A of Table 5 report the GRS test results of the variant asset pricing models and the $p$-value of GRS test statistic rejects the null hypothesis of zero intercepts of CAPM, FF three-factor, FF five-factor models along with the six-factor model for $2 \times 3$ sorts of Size-OP portfolios.

Panel A of Table 4 presents the GMM estimation result of $2 \times 3$ sorts of Size-Investment portfolios. The GMM estimation result infers that the human capital component of the sixfactor model significantly priced the variation in excess return on five of $2 \times 3$ sorts of SizeInvestment portfolios. Panel A of Table 5 present the GRS test results of the variant asset pricing models and the $p$-value of GRS test statistic rejects the null hypothesis of zero intercepts of CAPM, FF three-factor, and FF five-factor models albeit unable to reject the null hypothesis of the six-factor model for $2 \times 3$ sorts of Size-Investment portfolios. The average $A R^{2}$ of the six-factor model is 0.979 .

Portfolios of $5 \times 5$ sorts

Panel B of Table 4 presents the GMM estimation result for $5 \times 5$ sorts of Size-B/M portfolios. The GMM estimation result indicates that the human capital component of the six-factor model significantly approximates the variation in excess return on twelve of $5 \times 5$ sorts of Size-B/M portfolios. Panel B of Table 5 shows the GRS test results of variant asset pricing models in pricing the excess return on $5 \times 5$ sorts of Size-B/M portfolios. The $p$-value of GRS test statistic rejects the null hypothesis of zero intercepts of CAPM, FF three-factor, and FF five-factor models for $5 \times 5$ sorts of Size-B/M portfolios. Moreover, the $p$-value of GRS test statistic unable to reject the null hypothesis of zero intercepts of the six-factor asset pricing model and hence passes the GRS test for $2 \times 3$ sorts of Size-B/M portfolios. The average $A R^{2}$ of the six-factor model is 0.915 .

Panel B of Table 4 reports the GMM estimation result for $5 \times 5$ sorts of Size-OP portfolios. The GMM estimation result infers that the human capital component of the sixfactor model significantly priced the variation in excess return on five of $5 \times 5$ sorts of SizeOP portfolios. Panel B of Table 5 reports the GRS test results of variant asset pricing models, and the $p$-value of GRS test statistic rejects the null hypothesis of zero intercepts of CAPM, FF three-factor, FF five-factor models along with the six-factor model for $5 \times 5$ sorts of SizeOP portfolios. The average $A R^{2}$ of the six-factor model is 0.926 .

Panel B of Table 4 shows the GMM estimation result for $5 \times 5$ sorts of Size-Investment portfolios. The GMM estimation result indicates that the human capital component of the six-factor model significantly priced the variation in excess return on thirteen of $5 \times 5$ sorts of Size-Investment portfolios. Panel B of Table 5 present the GRS test results of variant asset pricing models and the $p$-value of GRS test statistic rejects the null hypothesis of zero intercepts of CAPM, FF three-factor, and FF five-factor models for $5 \times 5$ sorts of Size- 
Investment portfolios. Conversely, the $p$-value of GRS test statistic unable to reject the null hypothesis of zero intercepts of the six-factor model and passes the GRS test for $5 \times 5$ sorts of Size-Investment portfolios. The average $A R^{2}$ of the six-factor model is 0.699 .

Portfolios of $10 \times 10$ sorts

Panel C of Table 4 shows the GMM estimation result for $10 \times 10$ sorts of Size-B/M portfolios. The GMM estimation result infers that the human capital component of the six-factor model significantly priced the variation in excess return on thirty-eight of $10 \times 10$ sorts of Size-B/M portfolios. Panel $\mathrm{C}$ of Table 5 reports the GRS test results of variant asset pricing models in pricing the excess return on $10 \times 10$ sorts of Size-B/M portfolios. The $p$-value of GRS test statistic rejects the null hypothesis of zero intercepts of CAPM, FF three-factor, and FF fivefactor models albeit unable to reject the null hypothesis of the six-factor asset pricing model and hence passes the GRS test for $10 \times 10$ sorts of Size-B/M portfolios. The average $A R^{2}$ of the six-factor model is 0.791 .

Panel C of Table 4 presents the GMM estimation result for $10 \times 10$ sorts of Size-OP portfolios. The result shows that the human capital component of the six-factor model significantly priced the variation in excess return on twenty-six of $10 \times 10$ sorts of Size-OP portfolios. Panel $\mathrm{C}$ of Table 5 presents the GRS test results of variant asset pricing models in pricing the excess return on $10 \times 10$ sorts of Size-OP portfolios. The $p$-value of GRS test statistic rejects the null hypothesis of zero intercepts of CAPM, FF three-factor, and five-factor models but accept the null hypothesis of zero intercepts of the six-factor asset pricing model. The six-factor model passes the GRS test convincingly for $10 \times 10$ sorts of Size-OP portfolios. The average $A R^{2}$ of the six-factor model is 0.806 .

Panel C of Table 4 reports the GMM estimation result for $10 \times 10$ sorts of Size-Investment portfolios. The result infers that the human capital component of the six-factor model significantly priced the variation in excess return on twenty-three of $10 \times 10$ sorts of SizeInvestment portfolios. Panel $C$ of Table 5 shows the GRS test result of variant portfolios in approximating the excess return on $10 \times 10$ sorts of Size-Investment portfolios. The $p$-value of GRS test statistic rejects the null hypothesis of zero intercept of CAPM, FF three-factor, and five-factor models albeit unable to reject the null hypothesis of the six-factor model and hence passes the GRS test for $10 \times 10$ sorts of Size-Investment portfolios. The average $A R^{2}$ of the six-factor model is 0.810 .

Briefly, the human capital component of the six-factor asset pricing model significantly priced the variation in excess return on $2 \times 3,5 \times 5,10 \times 10$ sorts of FF portfolios. Further, the six-factor asset pricing model outperforms the CAPM, FF three-factor, and FF five-factor models in asset return predictability. 
R. Roy, S. Shijin / ACRN Journal of Finance and Risk Perspectives 8 (2019) 21 - xx

Table 4 GMM estimates of six-factor asset pricing model to explain excess returns on FF portfolios of $2 \times 3,5 \times 5,10 \times 10$ sorts

\begin{tabular}{|c|c|c|c|c|c|c|c|}
\hline & & LBR & RM-RF & SMB & HML & RMW & CMA \\
\hline \multicolumn{8}{|l|}{ Panel A: FF portfolios from $2 \times 3$ sorts } \\
\hline \multirow[t]{3}{*}{$2 \times 3$ sorts $(6$ Size-B/M portfolios $)$} & GMM & -0.002 & 1.016 & 0.414 & 0.228 & 0.024 & 0.021 \\
\hline & $A|z-\mu|$ & 1.875 & 103.670 & 28.917 & 13.770 & 4.448 & 3.095 \\
\hline & \# of significant portfolios & 3 & 6 & 4 & 6 & 6 & 5 \\
\hline \multirow[t]{3}{*}{$2 \times 3$ sorts $(6$ Size-OP portfolios) } & GMM & -0.001 & 1.016 & 0.391 & 0.099 & -0.017 & -0.022 \\
\hline & $A|z-\mu|$ & 1.625 & 83.940 & 25.697 & 6.478 & 19.110 & 3.425 \\
\hline & \# of significant portfolios & 3 & 6 & 6 & 6 & 5 & 4 \\
\hline \multirow[t]{3}{*}{$2 \times 3$ sorts $(6$ Size-Investment portfolios) } & GMM & 0.001 & 1.011 & 0.403 & 0.050 & -0.007 & 0.095 \\
\hline & $A|z-\mu|$ & 2.565 & 89.052 & 26.257 & 3.492 & 5.445 & 12.015 \\
\hline & \# of significant portfolios & 5 & 6 & 6 & 1 & 6 & 6 \\
\hline \multicolumn{8}{|l|}{ Panel B: FF portfolios from $5 \times 5$ sorts } \\
\hline \multirow[t]{3}{*}{$5 \times 5$ sorts $(25$ Size-B/M portfolios $)$} & GMM & -0.002 & 1.023 & 0.568 & 0.199 & 0.001 & 0.021 \\
\hline & $A|z-\mu|$ & 1.622 & 45.58 & 18.63 & 6.821 & 4.654 & 2.132 \\
\hline & \# of significant portfolios & 12 & 25 & 25 & 21 & 22 & 12 \\
\hline \multirow[t]{3}{*}{$5 \times 5$ sorts $(25$ Size-OP portfolios) } & GMM & 0.0001 & 1.024 & 0.477 & 0.113 & 0.059 & 0.009 \\
\hline & $A|z-\mu|$ & 1.005 & 52.227 & 16.529 & 4.337 & 10.054 & 2.035 \\
\hline & \# of significant portfolios & 5 & 25 & 25 & 21 & 24 & 13 \\
\hline \multirow[t]{3}{*}{$5 \times 5$ sorts ( 25 Size-Investment portfolios) } & GMM & 0.0105 & 1.003 & 0.545 & 0.116 & -0.005 & 0.121 \\
\hline & $A|z-\mu|$ & 1.971 & 35.285 & 13.925 & 2.730 & 3.065 & 4.166 \\
\hline & \# of significant portfolios & 13 & 25 & 25 & 16 & 17 & 20 \\
\hline
\end{tabular}




\section{Panel C: FF portfolios from $10 \times 10$ sorts}

$10 \times 10$ sorts $(100$ Size-B/M portfolios)

$10 \times 10$ sorts (100 Size-OP portfolios)

$10 \times 10$ sorts (100 Size-Investment portfolios)

$\begin{array}{lllllll}\text { GMM } & -0.008 & 1.035 & 0.540 & 0.245 & 0.036 & 0.013 \\ A|z-\mu| & 1.312 & 25.949 & 10.794 & 4.376 & 3.508 & 1.564 \\ \text { \# of significant portfolios } & 38 & 100 & 93 & 83 & 75 & 38 \\ \text { GMM } & -0.0002 & 1.012 & 0.543 & 0.154 & 0.080 & 0.011 \\ A|z-\mu| & 1.112 & 31.020 & 12.235 & 3.119 & 5.594 & 1.408 \\ \text { \# of significant portfolios } & 26 & 100 & 95 & 69 & 87 & 36 \\ \text { GMM } & 0.002 & 1.015 & 0.562 & 0.115 & 0.030 & 0.102 \\ A|z-\mu| & 1.174 & 29.706 & 11.649 & 2.590 & 3.410 & 2.898 \\ \text { \# of significant portfolios } & 23 & 100 & 94 & 61 & 76 & 65\end{array}$

Notes: The main results appearing in this table are averages of $2 \times 3,5 \times 5,10 \times 10$ sorts of FF portfolios. $A|z-\mu|$ is the average absolute z-mean for a set of regressions. z-statistics are in italics and are HAC (Newey \& West, 1987) corrected for GMM. The number of significant portfolios at the 5 and 10 percent level are labeled by \# of significant portfolios. The GMM estimate results of CAPM, FF three-factor, and FF five-factor models are not reported here but available with the authors upon request. 
R. Roy, S. Shijin / ACRN Journal of Finance and Risk Perspectives 8 (2019) 21 - xx

Table 5 Summary statistics of asset pricing tests for FF portfolios of $2 \times 3,5 \times 5,10 \times 10$ sorts

\begin{tabular}{|c|c|c|c|c|c|c|c|}
\hline & No. of FF portfolios & Asset pricing model & Model factors & GRS & $p(G R S)$ & $A\left|a_{i}\right|$ & $\mathrm{AR}^{2}$ \\
\hline \multicolumn{8}{|c|}{ Panel A: FF portfolios from $2 \times 3$ sorts } \\
\hline $2 \times 3$ sorts & 6 Size-B/M & CAPM & $R M-R F$ & 6.657 & 0.000 & 0.187 & 0.786 \\
\hline $2 \times 3$ sorts & 6 Size-B/M & FF three-factor model & $R M-R F S M B H M L$ & 6.413 & 0.000 & 0.130 & 0.966 \\
\hline $2 \times 3$ sorts & 6 Size-B/M & FF five-factor model & $R M-R F S M B H M L R M W C M A$ & 3.391 & 0.002 & 0.079 & 0.971 \\
\hline $2 \times 3$ sorts & 6 Size-B/M & Six-factor model & LBR RM-RF SMB HML RMW CMA & 1.382 & 0.220 & 0.260 & 0.972 \\
\hline $2 \times 3$ sorts & 6 Size-OP & CAPM & $R M-R F$ & 4.201 & 0.000 & 0.215 & 0.840 \\
\hline $2 \times 3$ sorts & 6 Size-OP & FF three-factor model & $R M-R F S M B H M L$ & 6.153 & 0.000 & 0.180 & 0.950 \\
\hline $2 \times 3$ sorts & 6 Size-OP & FF five-factor model & $R M-R F S M B H M L R M W C M A$ & 4.685 & 0.000 & 0.055 & 0.979 \\
\hline $2 \times 3$ sorts & 6 Size-OP & Six-factor model & LBR RM-RF SMB HML RMW CMA & 2.561 & 0.019 & 0.421 & 0.979 \\
\hline $2 \times 3$ sorts & 6 Size-Investment & CAPM & $R M-R F$ & 7.802 & 0.000 & 0.215 & 0.827 \\
\hline $2 \times 3$ sorts & 6 Size-Investment & FF three-factor model & $R M-R F S M B H M L$ & 8.549 & 0.000 & 0.139 & 0.960 \\
\hline $2 \times 3$ sorts & 6 Size-Investment & FF five-factor model & $R M-R F S M B H M L R M W C M A$ & 3.970 & 0.000 & 0.102 & 0.980 \\
\hline $2 \times 3$ sorts & 6 Size-Investment & Six-factor model & LBR RM-RF SMB HML RMW CMA & 1.200 & 0.305 & 0.206 & 0.980 \\
\hline \multicolumn{8}{|c|}{ Panel B: $F F$ portfolios from $5 \times 5$ sorts } \\
\hline $5 \times 5$ sorts & 25 Size-B/M & CAPM & $R M-R F$ & 4.964 & 0.000 & 0.214 & 0.723 \\
\hline $5 \times 5$ sorts & 25 Size-B/M & FF three-factor model & $R M-R F S M B H M L$ & 5.036 & 0.000 & 0.141 & 0.905 \\
\hline $5 \times 5$ sorts & 25 Size-B/M & FF five-factor model & $R M-R F S M B H M L R M W C M A$ & 4.253 & 0.000 & 0.133 & 0.914 \\
\hline $5 \times 5$ sorts & 25 Size-B/M & Six-factor model & LBR RM-RF SMB HML RMW CMA & 0.773 & 0.775 & 0.523 & 0.915 \\
\hline $5 \times 5$ sorts & 25 Size-OP & CAPM & $R M-R F$ & 21.967 & 0.000 & 0.225 & 0.780 \\
\hline $5 \times 5$ sorts & 25 Size-OP & FF three-factor model & $R M-R F S M B H M L$ & 28.284 & 0.000 & 0.166 & 0.899 \\
\hline $5 \times 5$ sorts & 25 Size-OP & FF five-factor model & $R M-R F S M B H M L R M W C M A$ & 25.620 & 0.000 & 0.080 & 0.926 \\
\hline $5 \times 5$ sorts & 25 Size-OP & Six-factor model & LBR RM-RF SMB HML RMW CMA & 21.485 & 0.000 & 0.451 & 0.926 \\
\hline $5 \times 5$ sorts & 25 Size-Investment & CAPM & $R M-R F$ & 3.416 & 0.000 & 0.260 & 0.557 \\
\hline $5 \times 5$ sorts & 25 Size-Investment & FF three-factor model & $R M-R F S M B H M L$ & 3.346 & 0.000 & 0.163 & 0.685 \\
\hline $5 \times 5$ sorts & 25 Size-Investment & FF five-factor model & $R M-R F S M B H M L R M W C M A$ & 2.514 & 0.000 & 0.106 & 0.696 \\
\hline $5 \times 5$ sorts & 25 Size-Investment & Six-factor model & LBR RM-RF SMB HML RMW CMA & 1.125 & 0.311 & 2.662 & 0.699 \\
\hline
\end{tabular}


R. Roy, S. Shijin / ACRN Journal of Finance and Risk Perspectives 8 (2019) 21 - 55

Panel C: FF portfolios from $10 \times 10$ sorts

\begin{tabular}{|c|c|c|c|c|c|c|c|}
\hline $10 \times 10$ sorts & 100 Size-B/M & CAPM & $R M-R F$ & 2.809 & 0.000 & 0.396 & 0.620 \\
\hline $10 \times 10$ sorts & 100 Size-B/M & FF three-factor model & $R M-R F S M B H M L$ & 2.883 & 0.000 & 0.335 & 0.779 \\
\hline $10 \times 10$ sorts & 100 Size-B/M & FF five-factor model & $R M-R F$ SMB HML RMW CMA & 2.491 & 0.000 & 0.315 & 0.791 \\
\hline $10 \times 10$ sorts & 100 Size-B/M & Six-factor model & LBR RM-RF SMB HML RMW CMA & 0.728 & 0.965 & 1.428 & 0.791 \\
\hline $10 \times 10$ sorts & 100 Size-OP & CAPM & $R M-R F$ & 1.876 & 0.000 & 0.272 & 0.663 \\
\hline $10 \times 10$ sorts & 100 Size-OP & FF three-factor model & $R M-R F S M B H M L$ & 1.822 & 0.000 & 0.217 & 0.782 \\
\hline $10 \times 10$ sorts & 100 Size-OP & FF five-factor model & $R M-R F S M B H M L R M W C M A$ & 1.614 & 0.001 & 0.171 & 0.804 \\
\hline $10 \times 10$ sorts & 100 Size-OP & Six-factor model & LBR RM-RF SMB HML RMW CMA & 1.112 & 0.254 & 1.222 & 0.806 \\
\hline $10 \times 10$ sorts & 100 Size-Investment & CAPM & $R M-R F$ & 2.039 & 0.000 & 0.296 & 0.658 \\
\hline $10 \times 10$ sorts & 100 Size-Investment & FF three-factor model & $R M-R F S M B H M L$ & 2.196 & 0.000 & 0.217 & 0.794 \\
\hline $10 \times 10$ sorts & 100 Size-Investment & FF five-factor model & $R M-R F$ SMB HML RMW CMA & 1.864 & 0.000 & 0.183 & 0.809 \\
\hline $10 \times 10$ sorts & 100 Size-Investment & Six-factor model & LBR RM-RF SMB HML RMW CMA & 1.190 & 0.142 & 1.287 & 0.810 \\
\hline
\end{tabular}

Notes: The GRS tests whether all intercepts in the six regressions are zero. $p(G R S)$ is the corresponding probability value of GRS test statistic. $A\left|a_{i}\right|$ is the average absolute intercept for a set of regressions. $\mathrm{AR}^{2}$, the average of the regression $\mathrm{R}^{2}$, adjusted for degrees of freedom. 
Portfolios of $2 \times 4 \times 4$ sorts

Table 6 reports the GMM estimation result for $2 \times 4 \times 4$ sorts of Size-B/M-OP portfolios. The GMM estimation result shows that the human capital component of the six-factor model significantly priced the variation in excess return on eleven of $2 \times 4 \times 4$ sorts of Size-B/M-OP portfolios. Following, Table 7 presents the GRS test results of CAPM, FF three-factor, FF five-factor, and the six-factor asset pricing models in pricing the excess returns on $2 \times 4 \times 4$ sorts of Size-B/M-OP portfolios. The $p$-value of GRS test statistic rejects the null hypothesis of zero intercepts of CAPM, FF three-factor, and FF five-factor models but unable to reject the null hypothesis of the six-factor asset pricing model and passes the GRS test convincingly for $2 \times 4 \times 4$ sorts of Size-B/M-OP portfolios. The average $A R^{2}$ of the six-factor model is 0.858 .

The GMM estimation result (Table 6) for $2 \times 4 \times 4$ sorts of Size-B/M-Investment portfolios infers that the human capital component of the six-factor model significantly priced the variation in excess return on nine of $2 \times 4 \times 4$ sorts of Size-B/M-Investment portfolios. Following, Table 7 shows the GRS test result of the variant models in pricing the excess return on $2 \times 4 \times 4$ sorts of Size-B/M-Investment portfolios. The $p$-value of GRS test statistic rejects the null hypothesis of zero intercepts of CAPM, FF three-factor, and FF five-factor models albeit unable to reject the null hypothesis of the six-factor asset pricing model and pass the GRS test for $2 \times 4 \times 4$ sorts of Size-B/M-Investment portfolios. The average $A R^{2}$ of the sixfactor model is 0.882 .

Table 6 presents the GMM estimation result for $2 \times 4 \times 4$ sorts of Size-OP-Investment portfolios. The GMM estimation result infers that the human capital component of the sixfactor model significantly priced the variation in excess return on thirteen of $2 \times 4 \times 4$ sorts of Size-OP-Investment portfolios. Following, Table 7 presents the GRS test results of variant asset pricing models in approximating the excess returns on $2 \times 4 \times 4$ sorts of Size-OPInvestment portfolios. The $p$-value of GRS test statistic rejects the null hypothesis of zero intercepts of CAPM, FF three-factor, and FF five-factor models but unable to reject the null hypothesis of the six-factor asset pricing model and passes the GRS test convincingly for $2 \times$ $4 \times 4$ sorts of Size-OP-Investment portfolios. The average $A R^{2}$ of the six-factor model is 0.883 .

Concisely, the human capital component of the six-factor asset pricing model significantly priced the variation in excess return on $2 \times 4 \times 4$ sorts of Size-B/M-OP, Size$\mathrm{B} / \mathrm{M}$-Investment, and Size-OP-Investment portfolios. Further, the six-factor asset pricing model outclasses the CAPM, FF three-factor, and FF five-factor models in asset return predictability. 
R. Roy, S. Shijin / ACRN Journal of Finance and Risk Perspectives 8 (2019) 21 - xx

Table 6 GMM estimates of six-factor asset pricing model to explain excess returns on FF portfolios of $2 \times 4 \times 4$ sorts

\begin{tabular}{|c|c|c|c|c|c|c|c|}
\hline & & LBR & RM-RF & SMB & HML & RMW & CMA \\
\hline \multirow[t]{3}{*}{$2 \times 4 \times 4$ sorts (32 Size-B/M-OP portfolios) } & GMM & 0.0006 & 1.036 & 0.419 & 0.233 & 0.096 & 0.015 \\
\hline & $A|z-\mu|$ & 1.228 & 36.951 & 11.743 & 5.972 & 5.343 & 1.936 \\
\hline & \# of significant portfolios & 11 & 32 & 22 & 26 & 28 & 15 \\
\hline \multirow[t]{3}{*}{$2 \times 4 \times 4$ sorts $(32$ Size-B/M-Investment portfolios) } & GMM & -0.001 & 1.019 & 0.421 & 0.223 & 0.096 & 0.127 \\
\hline & $A|z-\mu|$ & 1.386 & 38.123 & 13.470 & 6.142 & 3.887 & 4.342 \\
\hline & \# of significant portfolios & 9 & 25 & 23 & 25 & 21 & 23 \\
\hline \multirow[t]{3}{*}{$2 \times 4 \times 4$ sorts ( 32 Size-OP-Investment portfolios) } & GMM & -0.0002 & 1.014 & 0.402 & 0.115 & 0.056 & 0.085 \\
\hline & $A|z-\mu|$ & 1.408 & 39.008 & 13.024 & 4.203 & 6.651 & 3.832 \\
\hline & \# of significant portfolios & 13 & 32 & 22 & 27 & 29 & 27 \\
\hline
\end{tabular}

Notes: The main results appearing in this table are averages of the FF portfolios of $2 \times 4 \times 4$ sorts. $A|z-\mu|$ is the average absolute z-mean for a set of regressions. $z$-statistics are in italics and are HAC (Newey \& West, 1987) corrected for GMM. The number of significant portfolios at the 5 and 10 percent level are labeled by \# of significant portfolios. 
R. Roy, S. Shijin / ACRN Journal of Finance and Risk Perspectives 8 (2019) 21 - 55

Table 7 Summary statistics of asset pricing tests for FF portfolios of $2 \times 4 \times 4$ sorts

\begin{tabular}{|c|c|c|c|c|c|c|c|}
\hline & No. of FF portfolios & Asset pricing model & Model factors & $G R S$ & $p(G R S)$ & $A\left|a_{i}\right|$ & $\mathrm{AR}^{2}$ \\
\hline $2 \times 4 \times 4$ sorts & 32 Size-B/M-OP & CAPM & $R M-R F$ & 2.707 & 0.000 & 0.270 & $\begin{array}{l}0.68 \\
1\end{array}$ \\
\hline $2 \times 4 \times 4$ sorts & 32 Size-B/M-OP & FF three-factor model & $R M-R F S M B H M L$ & 2.734 & 0.000 & 0.170 & $\begin{array}{l}0.83 \\
7\end{array}$ \\
\hline $2 \times 4 \times 4$ sorts & 32 Size-B/M-OP & FF five-factor model & $R M-R F S M B H M L R M W C M A$ & 2.184 & 0.000 & 0.142 & $\begin{array}{l}0.85 \\
8\end{array}$ \\
\hline $2 \times 4 \times 4$ sorts & 32 Size-B/M-OP & Six-factor model & LBR RM-RF SMB HML RMW CMA & 1.465 & 0.054 & 0.902 & $\begin{array}{l}0.85 \\
8\end{array}$ \\
\hline $2 \times 4 \times 4$ sorts & 32 Size-B/M-Investment & CAPM & $R M-R F$ & 2.803 & 0.000 & 0.211 & $\begin{array}{l}0.70 \\
5\end{array}$ \\
\hline $2 \times 4 \times 4$ sorts & 32 Size-B/M-Investment & FF three-factor model & $R M-R F S M B H M L$ & 2.641 & 0.000 & 0.172 & $\begin{array}{l}0.86 \\
5\end{array}$ \\
\hline $2 \times 4 \times 4$ sorts & 32 Size-B/M-Investment & FF five-factor model & $R M-R F S M B H M L R M W C M A$ & 1.861 & 0.004 & 0.117 & $\begin{array}{l}0.88 \\
2\end{array}$ \\
\hline $2 \times 4 \times 4$ sorts & 32 Size-B/M-Investment & Six-factor model & LBR RM-RF SMB HML RMW CMA & 0.541 & 0.980 & 0.511 & $\begin{array}{l}0.88 \\
2\end{array}$ \\
\hline $2 \times 4 \times 4$ sorts & 32 Size-OP-Investment & CAPM & $R M-R F$ & 3.737 & 0.000 & 0.289 & $\begin{array}{l}0.72 \\
9\end{array}$ \\
\hline $2 \times 4 \times 4$ sorts & 32 Size-OP-Investment & FF three-factor model & $R M-R F S M B H M L$ & 3.859 & 0.000 & 0.222 & $\begin{array}{l}0.85 \\
5\end{array}$ \\
\hline $2 \times 4 \times 4$ sorts & 32 Size-OP-Investment & FF five-factor model & $R M-R F S M B H M L R M W C M A$ & 2.793 & 0.000 & 0.144 & $\begin{array}{l}0.88 \\
3\end{array}$ \\
\hline $2 \times 4 \times 4$ sorts & 32 Size-OP-Investment & Six-factor model & LBR RM-RF SMB HML RMW CMA & 1.308 & 0.129 & 0.772 & $\begin{array}{l}0.88 \\
3\end{array}$ \\
\hline
\end{tabular}

Notes: The GRS tests whether all intercepts in the six regressions are zero. $p(G R S)$ is the corresponding probability value of GRS test statistic. $A\left|a_{i}\right|$ is the average absolute intercept for a set of regressions. $\mathrm{AR}^{2}$, the average of the regression $\mathrm{R}^{2}$, adjusted for degrees of freedom. 


\section{FF Industry portfolios of variant sets}

Table 8 presents the GMM estimation result of 5, 10, 12, 17, 30, 48, and 49 FF Industry portfolios whereas Panel A, B, C, D, E, F, and G of Table 9 shows the GRS test result of variant models for $5,10,12,17,30,48$, and $49 \mathrm{FF}$ Industry portfolios respectively.

Table 8 reports the GMM estimation result for 5 Industry portfolios, and the estimation result infers that the human capital component of the six-factor model significantly priced the variation in excess return on four of 5 Industry portfolios. Following, panel A of Table 9 shows the GRS test result of CAPM, FF three-factor, FF five-factor, and the six-factor asset pricing models in pricing the excess returns on 5 Industry portfolios. The $p$-value of GRS test statistic rejects the null hypothesis of zero intercepts of CAPM, FF three-factor, and FF fivefactor models but unable to reject the null hypothesis of the six-factor model and hence passes the GRS test. The average $A R^{2}$ of the six-factor model is 0.745 .

The GMM result of 10 Industry portfolios indicates that the human capital measure of the six-factor model significantly priced the variation in excess return on five of 10 Industry portfolios. Panel B of Table 9 presents the GRS test result of the variant models in pricing the excess returns on 10 Industry portfolios. The $p$-value of GRS test statistic rejects the null hypothesis of zero intercepts of CAPM, FF three-factor, and FF five-factor models albeit unable to reject the null hypothesis of the six-factor model and pass the GRS test. The average $A R^{2}$ of the six-factor model is 0.699 .

The GMM result of 12 Industry portfolio infers that the human capital measure of the six-factor model significantly approximates the variation in excess return on five of 12 Industry portfolios. Panel $C$ of Table 9 shows the GRS test result of the variant models in pricing the excess return on 12 Industry portfolios. The $p$-value of GRS test statistic rejects the null hypothesis of zero intercepts of CAPM, FF three-factor, and FF five-factor models except for the six-factor model that passes the GRS test. The average $A R^{2}$ of the six-factor model is 0.713 .

Table 8 presents the GMM estimation results for 17 and 30 Industry portfolios, which indicates that the human capital component of the six-factor model significantly captures the variation in excess return on four of 17 and ten of 30 Industry portfolios. Following, panel D and $\mathrm{E}$ of Table 9 reports the GRS test result of the variant models in pricing the excess return on 17 and 30 Industry portfolios respectively. The $p$-value of GRS test statistic rejects the null hypothesis of zero intercepts of FF three-factor and five-factor models except for CAPM and the six-factor model and both of which passes the GRS test for 17 and 30 Industry portfolios. The average $A R^{2}$ of the six-factor model is 0.677 for 17 and 0.632 for 30 Industry portfolios.

Table 8 reports the GMM estimation results for 48 and 49 Industry portfolios, which infers that the human capital component of the six-factor model significantly priced the variation in excess return on twenty of 48 and twenty-one of 49 Industry portfolios. Following, panel $\mathrm{F}$ and $\mathrm{G}$ of Table 9 shows the GRS test result of the variant models in pricing the excess return on 48 and 49 Industry portfolios respectively. The $p$-value of GRS test statistic rejects the null hypothesis of zero intercepts of $\mathrm{FF}$ three-factor and five-factor models albeit unable to reject the null hypothesis for CAPM and the six-factor model and both of which passes the GRS test for 48 and 49 Industry portfolios. The average $A R^{2}$ of the six-factor model is 0.597 for 48 and 0.600 for 49 Industry portfolios.

Succinctly, the human capital measure of the six-factor asset pricing model significantly priced the variation in excess return on $5,10,12,17,30,48$, and $49 \mathrm{FF}$ Industry portfolios. 
Further, the six-factor asset pricing model passes the GRS test of Gibbons et al. (1989) and outperforms the FF three-factor and FF five-factor models in asset return predictability with the exception CAPM, which passes the GRS test for 17, 30, 48, and 49 FF Industry portfolios. In the successive section, we report the results of additional tests for robustness. 
R. Roy, S. Shijin / ACRN Journal of Finance and Risk Perspectives 8 (2019) 21 - Xx

Table 8 GMM estimates of six-factor asset pricing model to explain excess returns on FF Industry portfolios

\begin{tabular}{|c|c|c|c|c|c|c|c|}
\hline & & LBR & RM-RF & $\mathrm{SMB}$ & HML & RMW & CMA \\
\hline \multirow[t]{3}{*}{5 Industry portfolios } & GMM & -0.0007 & 0.997 & -0.017 & -0.014 & 0.148 & 0.108 \\
\hline & $A|z-\mu|$ & 2.168 & 31.898 & 2.050 & 4.328 & 4.874 & 2.254 \\
\hline & \# of significant portfolios & 4 & 5 & 2 & 3 & 5 & 5 \\
\hline \multirow[t]{3}{*}{10 Industry portfolios } & GMM & -0.001 & 0.985 & 0.011 & 0.068 & 0.174 & 0.145 \\
\hline & $A|z-\mu|$ & 1.409 & 24.791 & 2.117 & 3.340 & 3.836 & 2.155 \\
\hline & \# of significant portfolios & 4 & 10 & 6 & 6 & 7 & 7 \\
\hline \multirow[t]{3}{*}{12 Industry portfolios } & GMM & -0.0046 & 1.001 & 0.027 & 0.092 & 0.186 & 0.136 \\
\hline & $A|z-\mu|$ & 1.486 & 24.099 & 2.195 & 2.954 & 3.778 & 1.8625 \\
\hline & \# of significant portfolios & 5 & 12 & 6 & 7 & 7 & 7 \\
\hline \multirow[t]{3}{*}{17 Industry portfolios } & GMM & -0.009 & 1.053 & 0.156 & 0.179 & 0.236 & 0.091 \\
\hline & $A|z-\mu|$ & 1.251 & 26.524 & 2.877 & 2.969 & 4.917 & 1.315 \\
\hline & \# of significant portfolios & 4 & 18 & 12 & 12 & 13 & 4 \\
\hline \multirow[t]{3}{*}{30 Industry portfolios } & GMM & -0.010 & 1.078 & 0.179 & 0.140 & 0.295 & 0.138 \\
\hline & $A|z-\mu|$ & 1.402 & 20.386 & 2.583 & 2.670 & 4.204 & 1.849 \\
\hline & \# of significant portfolios & 10 & 30 & 19 & 16 & 22 & \\
\hline
\end{tabular}




\begin{tabular}{|c|c|c|c|c|c|c|c|}
\hline & & LBR & RM-RF & SMB & HML & RMW & CMA \\
\hline \multirow[t]{2}{*}{48 Industry portfolios } & GMM & -0.011 & 1.071 & 0.256 & 0.164 & 0.310 & 0.108 \\
\hline & \# of significant portfolios & 20 & 48 & 35 & 27 & 38 & 24 \\
\hline \multirow{2}{*}{49 Industry portfolios } & $A|z-\mu|$ & 1.382 & 17.875 & 3.202 & 2.626 & 4.215 & 1.715 \\
\hline & \# of significant portfolios & 21 & 49 & 36 & 27 & 38 & 24 \\
\hline
\end{tabular}

Notes: The main results appearing in this table are averages of the FF Industry portfolios. $A|z-\mu|$ is the average absolute z-mean for a set of regressions. $z-$ statistics are in italics and are HAC (Newey \& West, 1987) corrected for GMM. The number of significant portfolios at the 5 and 10 percent level are labeled by \# of significant portfolios. The GMM estimation results of CAPM, FF three-factor, and five-factor models are not reported here but available with the authors upon request. 
Table 9 Summary statistics of asset pricing tests for FF Industry portfolios

\begin{tabular}{|c|c|c|c|c|c|}
\hline & Model factors & GRS & $p(G R S)$ & $A\left|a_{i}\right|$ & $\mathrm{AR}^{2}$ \\
\hline \multicolumn{6}{|c|}{ Panel A: FF 5 Industry portfolios } \\
\hline CAPM & $R M-R F$ & 3.063 & 0.010 & 0.190 & 0.745 \\
\hline FF three-factor model & $R M-R F S M B H M L$ & 4.788 & 0.000 & 0.196 & 0.791 \\
\hline FF five-factor model & $R M-R F S M B H M L R M W C M A$ & 3.773 & 0.002 & 0.196 & 0.823 \\
\hline Six-factor model & LBR RM-RF SMB HML RMW CMA & 1.130 & 0.343 & 0.807 & 0.824 \\
\hline \multicolumn{6}{|c|}{ Panel B: FF 10 Industry portfolios } \\
\hline CAPM & $R M-R F$ & 1.888 & 0.045 & 0.215 & 0.611 \\
\hline FF three-factor model & $R M-R F S M B H M L$ & 3.217 & 0.000 & 0.218 & 0.664 \\
\hline FF five-factor model & RM-RF SMB HML RMW CMA & 2.391 & 0.009 & 0.183 & 0.698 \\
\hline Six-factor model & $L B R$ RM-RF SMB HML RMW CMA & 0.678 & 0.744 & 0.904 & 0.699 \\
\hline \multicolumn{6}{|c|}{ Panel C: FF 12 Industry portfolios } \\
\hline CAPM & $R M-R F$ & 2.037 & 0.020 & 0.207 & 0.627 \\
\hline FF three-factor model & $R M-R F S M B H M L$ & 3.102 & 0.000 & 0.211 & 0.680 \\
\hline FF five-factor model & RM-RF SMB HML RMW CMA & 2.386 & 0.005 & 0.189 & 0.696 \\
\hline Six-factor model & LBR RM-RF SMB HML RMW CMA & 0.668 & 0.781 & 0.843 & 0.713 \\
\hline \multicolumn{6}{|c|}{ Panel D: FF 17 Industry portfolios } \\
\hline CAPM & $R M-R F$ & 1.208 & 0.255 & 0.187 & 0.585 \\
\hline FF three-factor model & $R M-R F S M B H M L$ & 1.923 & 0.015 & 0.181 & 0.640 \\
\hline FF five-factor model & $R M-R F S M B H M L R M W C M A$ & 1.565 & 0.071 & 0.207 & 0.676 \\
\hline Six-factor model & LBR RM-RF SMB HML RMW CMA & 0.617 & 0.878 & 0.885 & 0.677 \\
\hline \multicolumn{6}{|c|}{ Panel E: FF 30 Industry portfolios } \\
\hline CAPM & $R M-R F$ & 1.102 & 0.330 & 0.201 & 0.546 \\
\hline FF three-factor model & $R M-R F S M B H M L$ & 1.707 & 0.013 & 0.221 & 0.596 \\
\hline
\end{tabular}


R. Roy, S. Shijin / ACRN Journal of Finance and Risk Perspectives 8 (2019) 21 - 55

\begin{tabular}{|c|c|c|c|c|c|}
\hline & Model factors & $G R S$ & $p(G R S)$ & $A\left|a_{i}\right|$ & $\mathrm{AR}^{2}$ \\
\hline FF five-factor model & RM-RF SMB HML RMW CMA & 1.742 & 0.011 & 0.241 & 0.632 \\
\hline Six-factor model & LBR RM-RF SMB HML RMW CMA & 0.694 & 0.885 & 1.208 & 0.632 \\
\hline
\end{tabular}

Panel F: FF 48 Industry portfolios

\begin{tabular}{|c|c|c|c|c|c|}
\hline CAPM & $R M-R F$ & 1.051 & 0.388 & 0.200 & 0.506 \\
\hline FF three-factor model & $R M-R F S M B H M L$ & 1.450 & 0.034 & 0.216 & 0.562 \\
\hline FF five-factor model & $R M-R F S M B H M L R M W C M A$ & 1.556 & 0.015 & 0.277 & 0.596 \\
\hline Six-factor model & LBR RM-RF SMB HML RMW CMA & 1.031 & 0.422 & 1.647 & 0.597 \\
\hline
\end{tabular}

Panel G: FF 49 Industry portfolios

\begin{tabular}{|c|c|c|c|c|c|}
\hline CAPM & $R M-R F$ & 1.093 & 0.321 & 0.202 & 0.510 \\
\hline FF three-factor model & $R M-R F S M B H M L$ & 1.577 & 0.012 & 0.219 & 0.565 \\
\hline FF five-factor model & $R M-R F S M B H M L R M W C M A$ & 1.546 & 0.015 & 0.281 & 0.599 \\
\hline Six-factor model & LBR RM-RF SMB HML RMW CMA & 1.084 & 0.334 & 1.667 & 0.600 \\
\hline
\end{tabular}

Notes: The GRS tests whether all intercepts in the six regressions are zero. $p(G R S)$ is the corresponding probability value of GRS test statistic. $A\left|a_{i}\right|$ is the average absolute intercept for a set of regressions. $\mathrm{AR}^{2}$, the average of the regression $\mathrm{R}^{2}$, adjusted for degrees of freedom. 


\section{Additional tests for robustness}

We use the wealth-to-consumption ratio (WCR) of Lustig et al. (2013) as an alternative measure of human capital. We substitute LBR with WCR as the measure of human capital in equation (8) representing the equilibrium six-factor asset pricing model, which yields

$$
\begin{aligned}
\boldsymbol{R}_{i t}-\boldsymbol{R}_{f t}= & \alpha_{i}+\beta_{1 i} W C \boldsymbol{R}_{t}+\beta_{2 i}(\boldsymbol{R M}-\boldsymbol{R F})_{t}+\beta_{3 i} S M B_{t}+\beta_{4 i} H M L_{t}+\beta_{5 i} R M W_{t}+\beta_{6 i} C M A_{t} \\
& +\varepsilon_{i t}
\end{aligned}
$$

We use equations (10) and (11) to evaluate the statistical and economic significance of equation (12) in asset return predictability. We employ the excess return on FF portfolios of $2 \times 3,5 \times 5,10 \times 10$ sorts, $2 \times 4 \times 4$ sorts, and the Industry portfolios to implement the above proposition.

Table 10 reports the GRS test results of the six-factor asset pricing model in pricing the excess return on $2 \times 3,5 \times 5,10 \times 10$ sorts of FF portfolios. Panel A, B, and C of Table 10 shows the GRS test results of the six-factor asset pricing model for $2 \times 3,5 \times 5,10 \times 10$ sorts of FF portfolios respectively. The $p$-value of GRS test statistic unable to reject the null hypothesis of zero intercepts of the six-factor asset pricing model for $2 \times 3$ and $10 \times 10$ sorts of FF portfolios with the exception for $5 \times 5$ sorts of FF portfolios. Hence, the six-factor asset pricing model passes the GRS test for $2 \times 3$ and $10 \times 10$ sorts of FF portfolios.

Table 11 presents the GRS test results of the six-factor asset pricing model in approximating the excess return on FF portfolios of $2 \times 4 \times 4$ sorts. The $p$-value of GRS test statistic unable to reject the null hypothesis of zero intercepts of the six-factor asset pricing model for FF portfolios of $2 \times 4 \times 4$ sorts on Size-B/M-Investment and passes the GRS test. Conversely, the $p$-value of GRS test statistic rejects the null hypothesis of zero intercepts of the six-factor asset pricing model and hence underperform for FF portfolios of $2 \times 4 \times 4$ sorts on Size-B/M-OP and Size-OP-Investment.

Table 12 shows the GRS test results of the six-factor asset pricing model in pricing the excess return on $5,10,12,17,30,48$, and $49 \mathrm{FF}$ Industry portfolios. The $p$-value of GRS test statistic unable to reject the null hypothesis of zero intercepts of the six-factor asset pricing model for $5,10,12,17,30$, and $48 \mathrm{FF}$ Industry portfolios and hence passes the GRS test. Conversely, a $p$-value of GRS test statistic rejects the null hypothesis of zero intercepts of the six-factor asset pricing model for $49 \mathrm{FF}$ Industry portfolios.

The robustness test results further confirm the performance of the equilibrium six-factor asset pricing model in approximating the variation in return predictability. In other words, the parameter estimation of the six-factor model is robust to the alternative definitions of the human capital component. Conclusively, the empirical results offer favorable evidence in support of the equilibrium six-factor asset pricing model, which outperforms the CAPM, FF three-factor, and FF five-factor models in return predictability.

The successive section accompanies the empirical interpretation of the results and the summary of the study. 
R. Roy, S. Shijin / ACRN Journal of Finance and Risk Perspectives 8 (2019) 21 - xx

Table 10 Summary statistics of asset pricing tests (with WCR measuring human capital) for FF portfolios of $2 \times 3,5 \times 5$, and $10 \times 10$ sorts

\begin{tabular}{|c|c|c|c|c|c|c|c|}
\hline & No. of FF portfolios & Asset pricing model & Model factors & GRS & $p(G R S)$ & $A\left|a_{i}\right|$ & $\mathrm{AR}^{2}$ \\
\hline \multicolumn{8}{|c|}{ Panel A: FF $2 \times 3$ sorted portfolios } \\
\hline $2 \times 3$ sorted & 6 Size-B/M & Six-factor model & $W C R$ RM-RF SMB HML RMW CMA & 3.226 & 0.004 & 0.566 & 0.972 \\
\hline $2 \times 3$ sorted & 6 Size-OP & Six-factor model & $W C R R M-R F S M B H M L R M W C M A$ & 5.084 & 0.000 & 0.096 & 0.979 \\
\hline $2 \times 3$ sorted & 6 Size-Investment & Six-factor model & WCR RM-RF SMB HML RMW CMA & 1.938 & 0.074 & 0.098 & 0.980 \\
\hline \multicolumn{8}{|c|}{ Panel B: FF $5 \times 5$ sorted portfolios } \\
\hline $5 \times 5$ sorted & 25 Size-B/M & Six-factor model & WCR RM-RF SMB HML RMW CMA & 2.306 & 0.000 & 0.149 & 0.915 \\
\hline $5 \times 5$ sorted & 25 Size-OP & Six-factor model & WCR RM-RF SMB HML RMW CMA & 48.626 & 0.000 & 0.111 & 0.926 \\
\hline $5 \times 5$ sorted & 25 Size-Investment & Six-factor model & $W C R$ RM-RF SMB HML RMW CMA & 1.700 & 0.000 & 0.021 & 0.699 \\
\hline \multicolumn{8}{|c|}{ Panel C: FF $10 \times 10$ sorted portfolios } \\
\hline $10 \times 10$ sorted & 100 Size-B/M & Six-factor model & $W C R R M-R F S M B H M L R M W C M A$ & 1.194 & 0.138 & 0.239 & 0.791 \\
\hline $10 \times 10$ sorted & 100 Size-OP & Six-factor model & WCR RM-RF SMB HML RMW CMA & 0.113 & 0.251 & 0.192 & 0.805 \\
\hline $10 \times 10$ sorted & 100 Size-Investment & Six-factor model & WCR RM-RF SMB HML RMW CMA & 1.232 & 0.099 & 0.258 & 0.810 \\
\hline
\end{tabular}

Notes: The GRS tests whether all intercepts in the six regressions are zero. $p(G R S)$ is the corresponding probability value of GRS test statistic. $A\left|a_{i}\right|$ is the average absolute intercept for a set of regressions. $\mathrm{AR}^{2}$, the average of the regression $\mathrm{R}^{2}$, adjusted for degrees of freedom.

Table 11 Summary statistics of asset pricing tests (with WCR measuring human capital) for FF portfolios of $2 \times 4 \times 4$ sorts

\begin{tabular}{|c|c|c|c|c|c|c|c|}
\hline & No. of FF portfolios & Asset pricing model & Model factors & GRS & $p(G R S)$ & $A\left|a_{i}\right|$ & $\mathrm{AR}^{2}$ \\
\hline $2 \times 4 \times 4$ sorted & 32 Size-B/M-OP & Six-factor model & WCR RM-RF SMB HML RMW CMA & 1.950 & 0.002 & 0.199 & 0.858 \\
\hline $2 \times 4 \times 4$ sorted & 32 Size-B/M-Investment & Six-factor model & WCR RM-RF SMB HML RMW CMA & 0.756 & 0.828 & 0.138 & 0.882 \\
\hline $2 \times 4 \times 4$ sorted & 32 Size-OP-Investment & Six-factor model & $W C R$ RM-RF SMB HML RMW CMA & 2.444 & 0.000 & 0.197 & 0.883 \\
\hline
\end{tabular}

Notes: The GRS tests whether all intercepts in the six regressions are zero. $p(G R S)$ is the corresponding probability value of GRS test statistic. $A\left|a_{i}\right|$ is the average absolute intercept for a set of regressions. $\mathrm{AR}^{2}$, the average of the regression $\mathrm{R}^{2}$, adjusted for degrees of freedom. 
R. Roy, S. Shijin / ACRN Journal of Finance and Risk Perspectives 8 (2019) 21 - 55

Table 12 Summary statistics of asset pricing tests (with WCR measuring human capital) for FF Industry portfolios

\begin{tabular}{|c|c|c|c|c|c|c|}
\hline & Asset pricing model & Model factors & GRS & $p(G R S)$ & $A\left|a_{i}\right|$ & $\mathrm{AR}^{2}$ \\
\hline 5 Industry portfolios & Six-factor model & WCR RM-RF SMB HML RMW CMA & 1.835 & 0.105 & 0.171 & 0.824 \\
\hline 10 Industry portfolios & Six-factor model & WCR RM-RF SMB HML RMW CMA & 0.953 & 0.484 & 0.168 & 0.699 \\
\hline 12 Industry portfolios & Six-factor model & WCR RM-RF SMB HML RMW CMA & 0.677 & 0.772 & 0.166 & 0.713 \\
\hline 17 Industry portfolios & Six-factor model & WCR RM-RF SMB HML RMW CMA & 0.825 & 0.663 & 0.203 & 0.677 \\
\hline 30 Industry portfolios & Six-factor model & WCR RM-RF SMB HML RMW CMA & 0.974 & 0.508 & 0.272 & 0.632 \\
\hline 48 Industry portfolios & Six-factor model & WCR RM-RF SMB HML RMW CMA & 1.318 & 0.088 & 0.347 & 0.597 \\
\hline 49 Industry portfolios & Six-factor model & WCR RM-RF SMB HML RMW CMA & 1.403 & 0.047 & 0.354 & 0.600 \\
\hline
\end{tabular}

Notes: The GRS tests whether all intercepts in the six regressions are zero. $p(G R S)$ is the corresponding probability value of GRS test statistic. $A\left|a_{i}\right|$ is the average absolute intercept for a set of regressions. $\mathrm{AR}^{2}$, the average of the regression $\mathrm{R}^{2}$, adjusted for degrees of freedom. 


\section{Empirical interpretation and summary}

The present study develops an intertemporal framework where human capital component and the common factors jointly estimate the risks associated with an asset. Primarily, we examine the joint dynamics of the human capital component and common factors in asset return predictability. In the second stage, we investigate whether the human capital component is an unaccounted pricing factor of FF five-factor asset pricing model. In other words, Is human capital the sixth factor of $\mathrm{FF}$ five-factor asset pricing model?

The human capital component, market portfolio, size, value, profitability, and investment are the pricing factors in the intertemporal six-factor asset pricing framework developed in the study. The study period covers thirty years of time-series data. We include the frequently used asset pricing models that are well documented in the asset pricing literature, CAPM, FF three-factor model, FF five-factor model, along with the equilibrium six-factor model to capture the patterns in excess return on FF portfolios of $2 \times 3,5 \times 5,10 \times$ 10 sorts, $2 \times 4 \times 4$ sorts, and FF Industry portfolios. We use GMM estimation for estimating the parameters of the variant asset pricing models and GRS test statistics for evaluating the statistical and economic performance of the asset pricing models.

The conclusions are drawn in three phases. First, the GMM estimation result infers that the human capital component of the equilibrium six-factor asset pricing framework significantly priced the variation in excess return on the FF portfolios of $2 \times 3,5 \times 5,10 \times 10$ sorts, $2 \times 4 \times 4$ sorts, and FF Industry portfolios. Furthermore, the empirical results reveal that the sensitivity of the human capital component priced separately in the presence of the market portfolio and the common factors. Second, the GRS test of Gibbons et al. (1989) rejects the null hypothesis of zero intercepts of CAPM, FF three-factor model, and FF fivefactor model across the FF portfolios of variant sorts and for FF Industry portfolios, and hence rejected. In turn, the equilibrium six-factor asset pricing model pass the GRS test for FF portfolios of $2 \times 3,5 \times 5,10 \times 10$ sorts, $2 \times 4 \times 4$ sorts, and for FF Industry portfolios. Thus, the six-factor asset pricing model outperformed the variant asset pricing models in the return predictability. Third, the GMM estimation and GRS test results indicate that the proposed equilibrium six-factor asset pricing model is statistically and economically feasible of assessing the variation in excess return on the variant $\mathrm{FF}$ portfolios.

The contemporaneous asset pricing literature has witnessed the greater success of the factor-based asset pricing models to capture the patterns in expected returns, prominent among is the FF three-factor model and the FF five-factor model. However, the empirical success of the FF five-factor model is marred by its inability to capture the patterns in return on the small stock. Following Fama \& French (2016) in US, Kubota \& Takehara (2018) in Japan, Foye (2018) in emerging markets, and Roy \& Shijin (2018b, 2018c) in emerging and developed economies confirm the failure of the FF five-factor asset pricing model in return predictability. We argue in line with Pantzalis \& Park (2009), that the FF five-factor model fails in return predictability because of its inability to capture the risk related to the human capital component (Roy \& Shijin, 2018b). Thus, by developing an intertemporal asset pricing framework, which accommodates the human capital component, market portfolio, and the common factors, enables to answer the unresolved puzzle present in the asset pricing literature. The resultant equilibrium six-factor asset pricing model jointly address the two issues, first, the inability of FF five-factor asset pricing model to relate risk associated with 
human capital component causing its failure, and second, by addressing the joint dynamics of human capital and financial wealth in asset return predictability. Summarily, we argue that the human capital component is an unaccounted pricing factor of the FF five-factor asset pricing model and hence we claim that the human capital is the sixth factor of FF five-factor model. The findings that the human capital component is a significant component and pricing factor in asset return predictability remains robust to the alternative definitions of human capital. The key result of the study that human capital is an essential component in asset return predictability is in line with the empirical evidence of Eiling (2013). We present the concluding remarks in the successive section.

\section{Concluding remarks}

The intriguing puzzle plagued in the financial literature is how to discounting the risk premium and what are the economic forces determine the price of the risk. The joint dynamics of human wealth and financial wealth drives the dynamics governing the aggregate wealth is well established in the asset pricing literature. The risk of an asset is measured by the covariance of asset's return with the return on all invested wealth of an economy. Concurrently, we argue that the measure of all invested wealth of an economy is governed by the joint dynamics of the human capital component and the financial wealth.

The asset pricing literature has witnessed two types of proponents in pricing the risk of an asset, first, measures the risks of an asset risk by the covariance of its return with the return on market portfolio and the common factors. The second proponent estimates the asset's risks by the covariance of asset's return with the return on human wealth and financial wealth. We develop an integrated asset pricing framework consisting of the human capital component, market portfolio, size, value, profitability, and investment as priced factors, which carries the arguments of both the proponents. We test the equilibrium six-factor asset pricing framework on FF portfolios of variant sorts along with the Industry portfolios. The six-factor model performs better than CAPM, FF three-factor model, and FF five-factor asset pricing model across the variant FF portfolios. Further, the empirical results infer that the sensitivity to human capital component priced separately in the presence of market portfolio and the FF pricing factors. The empirical success of the integrated six-factor asset pricing model in return predictability mainly supports our claim that the human capital component and the financial wealth jointly govern the risks of an asset.

Conclusively, our findings contribute to the contemporaneous literature in several ways. First, the present study adds to the existing body of literature on ICAPM approaches (Campbell, 1996, 2000; Palacios, 2015; Pantzalis \& Park, 2009). These studies instigated that both the human capital and financial wealth are the equally good components in asset return predictability. Second, to the best of our knowledge there exist no literature or study on multifactor asset pricing model in an ICAPM framework consisting of the human capital component along with the pricing factors of $\mathrm{FF}$ five-factor model in return predictability. Hence, our equilibrium six-factor asset pricing framework is a significant contribution equally in asset return predictability and ultimately to the asset pricing literature. Third, we argue that the failure of FF five-factor asset pricing model in return predictability is because of its inability to relate risk associated with the human capital component. Further, we claim that the human capital is the missing and the sixth factor of FF five-factor asset pricing model. 
Fourth, our core contribution to the asset pricing literature is the equilibrium six-factor asset pricing model in an ICAPM framework, which provides an integrated platform that helps to narrow the differences among the two proponents and draw the mutual consensus.

The empirical results and findings equally pose the more significant implications to the decision-making process of the rational investor, institutional managers, portfolio managers, fund managers in formulating the better investment strategies that can help to diversify the aggregate risks.

\section{Acknowledgment}

The corresponding author acknowledges that the present work is the part of unpublished doctoral dissertation 'Essays in the nexus of Asset pricing, Human capital, Volatility, and Economic growth: The World evidence.'

\section{Conflict of interest statement}

The authors declare no conflict of interest.

\section{References}

Berk, J. B., \& Walden, J. (2013). Limited Capital Market Participation and Human Capital Risk. Review of Asset Pricing Studies, 3(1), 1-37. Retrieved from http://raps.oxfordjournals.org/content/3/1/1.short

Betermier, S., Jansson, T., Parlour, C., \& Walden, J. (2012). Hedging labor income risk. Journal of Financial Economics, 105(3), 622-639. Elsevier. Retrieved from http://dx.doi.org/10.1016/j.jfineco.2012.05.001

Blume, M. E., \& Friend, I. (1973). A New Look at the Capital Asset Pricing Model. The Journal of Finance, 28(1), 19-33. Retrieved December 4, 2016, from http://www.jstor.org/stable/2978165?origin=crossref

Campbell, J. Y. (1996). Understanding risk and return. Journal of Political Economy, 104(2), 298-345. Retrieved May 15, 2016, from http://dx.doi.org/10.1086/262026

Campbell, J. Y. (2000). Asset Pricing at the Millenium. Journal of Finance, 55(4), 1515-1567. Blackwell Publishers, Inc. Retrieved May 15, 2016, from http://doi.wiley.com/10.1111/0022-1082.00260

Campbell, J. Y. (2015). Emerging Trends: Asset Pricing. Emerging Trends in the Social and Behavioral Sciences (pp. 1-18). Hoboken, NJ, USA: John Wiley \& Sons, Inc. Retrieved May 19, 2017, from http://doi.wiley.com/10.1002/9781118900772.etrds0015

Carhart, M. M. (1997). On Persistence in Mutual Fund Performance. The Journal of Finance, 52(1), 57-82. Retrieved May 16, 2016, from http://www.jstor.org/stable/2329556?origin=crossref

Chen, N.-F., Roll, R., \& Ross, S. A. (1986). Economic Forces and the Stock Market. Source: The Journal of Business, 59(3), 383-403.

Eiling, E. (2013). Industry-Specific Human Capital, Idiosyncratic Risk, and the Cross-Section of Expected Stock Returns. The Journal of Finance, 68(1), 43-84. Retrieved from http://dx.doi.org/10.1111/j.15406261.2012.01794.x

Fama, E. F., \& French, K. R. (1993). Common risk factors in the returns on stocks and bonds. Journal of Financial Economics, 33(1), 3-56.

Fama, E. F., \& French, K. R. (2015). A five-factor asset pricing model. Journal of Financial Economics (Vol. 116). Retrieved May 16, 2016, from http://linkinghub.elsevier.com/retrieve/pii/S0304405X14002323

Fama, E. F., \& French, K. R. (2016). Dissecting Anomalies with a Five-Factor Model. Review of Financial Studies, 29(1), 69-103. Retrieved May 16, 2016, from http://rfs.oxfordjournals.org/lookup/doi/10.1093/rfs/hhv043 
Fama, E. F., \& French, K. R. (2017). International tests of a five-factor asset pricing model. Journal of Financial Economics, 123(3), 441-463. Elsevier B.V. Retrieved from http://dx.doi.org/10.1016/j.jfineco.2016.11.004

Fama, E. F., \& Schwert, G. W. (1977). Human capital and capital market equilibrium. Journal of Financial Economics, 4(1), 95-125. Retrieved September 5, 2017, from http://linkinghub.elsevier.com/retrieve/pii/0304405X77900381

Foye, J. (2018). A comprehensive test of the Fama-French five-factor model in emerging markets. Emerging Markets Review, 37, 199-222. Elsevier. Retrieved from https://doi.org/10.1016/j.ememar.2018.09.002

French, K. R. (2019). Kenneth R. French - Data Library. mba.tuck.dartmouth.edu. Retrieved from http://mba.tuck.dartmouth.edu/pages/faculty/ken.french/data_library.html

Gibbons, M. R., Ross, S. A., \& Shanken, J. (1989). A Test of the Efficiency of a Given Portfolio. Econometrica, 57(5), 1121-1152. Retrieved September 22, 2016, from http://www.jstor.org/stable/1913625?origin=crossref

Gregoriou, G., Racicot, F.-E., \& Théoret, R. (2016). The q -factor and the Fama and French asset pricing models: hedge fund evidence. Managerial Finance, 42(12), 1180-1207. Retrieved from http://www.emeraldinsight.com/doi/10.1108/MF-01-2016-0034

Jagannathan, R., \& Wang, Z. (1996). The Conditional CAPM and the Cross-Section of Expected Returns. Journal of Finance, 51(1), 3-53. Blackwell Publishing Ltd. Retrieved May 15, 2016, from http://doi.wiley.com/10.1111/j.1540-6261.1996.tb05201.x

Kubota, K., \& Takehara, H. (2018). Does the Fama and French Five-Factor Model Work Well in Japan? International Review of Finance, 18(1), 137-146. Retrieved May 2, 2017, from http://doi.wiley.com/10.1111/irfi.12126

Lettau, M., \& Ludvigson, S. C. (2001). Consumption, Aggregate Wealth, and Expected Stock Returns. Journal of Finance, 56(3), 815-849. Blackwell Publishers, Inc. Retrieved May 16, 2016, from http://doi.wiley.com/10.1111/0022-1082.00347

Lintner, J. (1965). The Valuation of Risk Assets and the Selection of Risky Investments in Stock Portfolios and Capital Budgets. The Review of Economics and Statistics, 47(1), 13-37. The MIT Press. Retrieved May 16, 2016, from http://www.jstor.org/stable/1926735

Lustig, H., \& Van Nieuwerburgh, S. G. (2008). The returns on human capital: Good news on wall street is bad news on main street. Review of Financial Studies, 21(5), 2097-2137.

Lustig, H., Van Nieuwerburgh, S. G., \& Verdelhan, A. (2013). The Wealth-Consumption Ratio. Review of Asset Pricing Studies, 3(1), 38-94. Retrieved May 16, 2016, from http://raps.oxfordjournals.org/lookup/doi/10.1093/rapstu/rat002

Mayers, D. (1972). Nonmarketable assets and capital market equilibrium under uncertainty. In Michael C. Jensen (Ed.), Studies in the Theory of Capital Markets (pp. 223-248). New York: Praeger Publishers.

Merton, R. C. (1973). An Intertemporal Capital Asset Pricing Model. Econometrica, 41(5), 867-887. Retrieved May 22, 2016, from http://www.jstor.org/stable/1913811?origin=crossref

Mossin, J. (1966). Equilibrium in a Capital Asset Market. Econometrica, 34(4), 768-783. Retrieved from http://www.jstor.org/stable/1910098

Newey, W. K., \& West, K. D. (1987). A Simple, Positive Semi-Definite, Heteroskedasticity and Autocorrelation Consistent Covariance Matrix. Econometrica, 55(3), 703-708. Retrieved December 15, 2016, from http://www.jstor.org/stable/1913610?origin=crossref

Olea, J. L. M., \& Pflueger, C. (2013). A Robust Test for Weak Instruments. Journal of Business \& Economic Statistics, $31(3), \quad 358-369 . \quad$ Retrieved from http://www.tandfonline.com/doi/abs/10.1080/00401706.2013.806694

Palacios, M. (2015). Human Capital as an Asset Class Implications from a General Equilibrium Model. Review of Financial Studies, 28(4), 978-1023. Retrieved May 19, 2016, from http://rfs.oxfordjournals.org/cgi/doi/10.1093/rfs/hhu073

Pantzalis, C., \& Park, J. C. (2009). Equity market valuation of human capital and stock returns. Journal of Banking \& Finance, 33(9), 1610-1623. Retrieved May 18, 2016, from http://linkinghub.elsevier.com/retrieve/pii/S0378426609000557

Racicot, F.-E., \& Rentz, W. F. (2016). A panel data robust instrumental variable approach: a test of the new Fama-French five-factor model. Applied Economics Letters, 24(6), 410-416. Retrieved May 22, 2016, from http://www.tandfonline.com/doi/full/10.1080/13504851.2015.1080798 
Ren, Y., Yuan, Y., \& Zhang, Y. (2014). Human capital, household capital and asset returns. Journal of Banking \& Finance, 42(1), 11-22. Retrieved May 19, 2017, from http://www.sciencedirect.com/science/article/pii/S0378426614000429

Roll, R. (1977). A critique of the asset pricing theory's tests Part I: On past and potential testability of the theory. Journal of Financial Economics, 4(2), 129-176. Retrieved May 16, 2016, from http://linkinghub.elsevier.com/retrieve/pii/0304405X77900095

Roy, R., \& Shijin, S. (2018a). Dissecting anomalies and dynamic human capital: The global evidence. Borsa Istanbul Review, $18(1), \quad 1-32 . \quad$ Retrieved from http://linkinghub.elsevier.com/retrieve/pii/S2214845017300637

Roy, R., \& Shijin, S. (2018b). A six-factor asset pricing model. Borsa Istanbul Review, 18(3), 205-217. Retrieved from http://linkinghub.elsevier.com/retrieve/pii/S2214845017301916

Roy, R., \& Shijin, S. (2018c). The nexus of anomalies-stock returns-asset pricing models: The international evidence. Borsa Istanbul Review. https://linkinghub.elsevier.com/retrieve/pii/S2214845018300152

Santos, T., \& Veronesi, P. (2006). Labor Income and Predictable Stock Returns. Review of Financial Studies, 19(1), 1-44. Retrieved May 21, 2016, from http://rfs.oxfordjournals.org/lookup/doi/10.1093/rfs/hhj006

Sharpe, W. F. (1964). Capital Asset Prices: A theory of market equilibirium under conditions of risk. The Journal of Finance, 19(3), 425-442. Retrieved May 16, 2016, from http://www.jstor.org/stable/2977928?origin=crossref

Sousa, R. M. (2012a). Wealth-to-income ratio, government bond yields and financial stress in the Euro Area. Applied Economics Letters, 19(11), 1085-1088. Retrieved from http://www.tandfonline.com/doi/abs/10.1080/13504851.2011.613751

Sousa, R. M. (2012b). Wealth-to-income ratio and stock returns: evidence from the Euro Area. Applied Economics $\begin{array}{llll}\text { Letters, } & 19(7), & 619-622 . & \text { Retrieved }\end{array}$ http://www.tandfonline.com/doi/abs/10.1080/13504851.2011.591723 